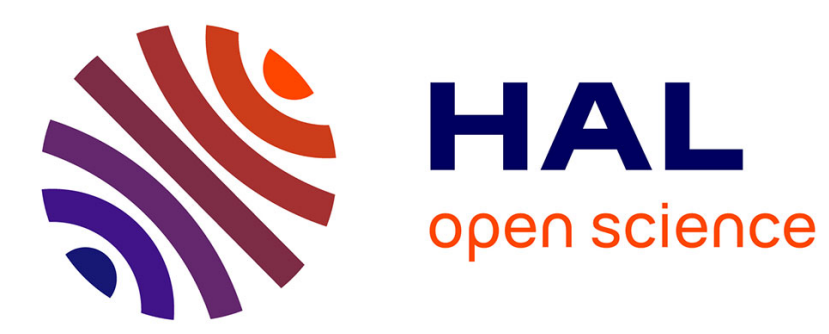

\title{
Mechanical properties of some polymers and composites at Strain Rates of $1000 / \mathrm{s}$
}

\author{
A. Bragov, A. Lomunov
}

\section{To cite this version:}

A. Bragov, A. Lomunov. Mechanical properties of some polymers and composites at Strain Rates of 1000/s. Journal de Physique IV Proceedings, 1994, 04 (C8), pp.C8-337-C8-342. 10.1051/jp4:1994851 . jpa-00253411

\section{HAL Id: jpa-00253411 https://hal.science/jpa-00253411}

Submitted on 1 Jan 1994

HAL is a multi-disciplinary open access archive for the deposit and dissemination of scientific research documents, whether they are published or not. The documents may come from teaching and research institutions in France or abroad, or from public or private research centers.
L'archive ouverte pluridisciplinaire HAL, est destinée au dépôt et à la diffusion de documents scientifiques de niveau recherche, publiés ou non, émanant des établissements d'enseignement et de recherche français ou étrangers, des laboratoires publics ou privés. 


\title{
Mechanical properties of some polymers and composites at Strain Rates of $1000 / \mathrm{s}$
}

A.M. Bragov and A.K. Lomunov

Research Institute of Mechanics, University of Nizhny Novgorod, 23 Gagarin Avenue, Building 6, 603600 Nizhny Novgorod, GSP-1000, Russian Federation, Russia

\begin{abstract}
Résumé: On présente les résultats des essais dynamiques de trois polymères (polycarbonate, polyamide et polyéthylène téréphtalate), d'un plastique renforcé à la fibre de verre, et d'organoplastique de troid types de renforcement chacun. Les essais de compression des éprouvettes à la vitesse de déformation d'environ $10^{3} \mathrm{~s}^{-1}$ sont effectués suivant la méthode de Kolsky avec la barre d'Hopkinson. Pour tous les matériaux, les diagrammes dynamiques de compression et les histoires de la vitesse de déformation sont obtenus. On note l'accroissement du module d'élasticité et des efforts de rupture avec l'accroissement de la vitsse de déformation. Pour le plastique renforcé par fibres de verre et pour l'organoplastique, ces paramètres sont aussi affectés par le type du renfort.
\end{abstract}

\begin{abstract}
Dynamic compression test results are presented for three polymers (polycarbonate, polyamide, and polyethylene terephtalate) and for two composite materials, a plain weave glass/epoxy with three different stacking sequences, and an aramid/epoxy (organoplastic material). Compression tests at a strain rate of about $10^{3} \mathrm{~s}^{-1}$ were conducted using the Kolsky method with the split Hopkinson pressure bar (SHPB). Dynamic compression diagrams and strain-rate histories were obtained for all the materials. An increase in the modulus of elasticity and in the fracture stress with strain rate was observed. For the glassreinforced plastic and organoplastic, these parameters are also affected by the reinforcement geometry.
\end{abstract}

\section{INTRODUCTION}

Due to their unique properties and the ever growing deficiency of metals, polymers and composites are now coming to be widely used in modern technology for producing critical units and parts undergoing dynamic pulsed loads of various kinds (impact, explosion, electro-magnetic, thermal, and other pulsed fields, etc.). To accurately and rationally design and analyze the response of such dynamically loaded structures, a good insight into the mechanical material properties for the related working strain rates is needed. Earlier the interest in analyzing material response under pulsed loads arose mainly from the needs of the defence technology. In recent years, however, numerous specialists designing, for example, containment buildings for the aircraft and energy industries, etc., have also. had to address these issues.

Today, there is only a limited amount of published work analyzing the mechanical properties of polymers. The split Hopkinson pressure bar (SHPB) method originally proposed by Kolsky [7] is one of the most popular experimental methods to provide success in the field of dynamic testing. 
It should be noted that recently the SHPB method and its modifications have come to be widely used in testing polymers and composites. This report presents dynamic test results for unreinforced polyamide, polycarbonate and polyethylene terephthalate (PET), and for glass-reinforced plastic and organoplastic with different reinforcement geometries. The tests were conducted using the Kolsky bar (SHPB) in compression.

\section{EXPERIMENTAL APPARATUS}

The polymeric and composite materials were tested on a split Hopkinson bar apparatus with bars of 10 and $20 \mathrm{~mm}$ diameter. The loading pulses were generated using strikers of different lengths accelerated in 10 or $20 \mathrm{~mm}$ diameter gas-guns. The strain pulses in the pressure bars were measured using small-base foil strain gauges cemented in the middle of the pressure bars. The signals from the strain gauges were stored in a digital oscilloscope and transmitted to an IBM PC-type computer for processing. The processing of the experimental data is automated using a specialized computer code that controls the calibration of the measuring channels, and computes the stresses, strains, and strain rates in the specimen based on Kolsky's formulae. To process the strain pulses, a fairly accurate synchronization between them, involving the intuitive choice of the time zero for each pulse, is required. As the rise time of the transmitted pulse in the tests with the polymers is considerably longer than that for the reflected pulse, a certain inaccuracy in choosing the reference points for these pulses is possible, even if the registering strain gauges are equidistant from the specimen. Inaccuracy in choosing the reference points for the pulses usually leads to an inadequate reconstruction of the dynamic stress-strain diagram, especially in its early stages. To allow for this, therefore, an algorithm was developed and a computer code written to allow for the automatic synchronization between the pulses, based on satisfying the main assumption if the Kolsky method, i.e. that of equilibrium of forces across the ends of the specimen during the entire deformation process. In addition, the code allows one to schedule the experiments, to carry out the statistical analysis of the results, and to plot the regression models. The information obtained is displayed in the form of tables and diagrams. It should be pointed out that the use of automated processing substantially reduces the time for processing the experimental data. At strain rates exceeding 2000/s a correction of the measured stresses, including a correction for the effect of inertia, was performed in accordance with the criterion first suggested by Davies and Hunter [8].

\section{SPECIMENS}

The three polymers (polyamide, PET, and polycarbonate) were tested using $9 \mathrm{~mm}$ diameter by $4.5 \mathrm{~mm}$ long specimens. A minimisation of the influence of friction forces on the results obtained was achieved by careful machining of the specimen surfaces and by smearing a thin layer of the lubricant $\mathrm{MoS}_{2}$ on the ends of the pressure bars and the specimen.

The glass-reinforced plastic specimens were cut out of $400 \mathrm{~mm}$ by $400 \mathrm{~mm}$ by $12 \mathrm{~mm}$ slabs manufactured by pressing unidirectional glass sheets with epoxy resin as the binder. The slabs differed in the relative orientation of the glass sheets: unidirectional (the angle between the imaginary axis of the slab and the direction of the reinforcing fibres in all the layers is $0^{\circ}$ ); cross-ply (where adjacent layers alternate with the angle between the fibre direction and the slab axis equal to either $0^{\circ}$ or $90^{\circ}$ ); and quasi-isotropic (with the angles between successive layers being in the order $0^{\circ},+45^{\circ}$, $90^{\circ}$, and $-45^{\circ}$ ). In all the reinforcement geometries the binder content was $25 \%$. Bars of $12 \mathrm{~mm}$ by $12 \mathrm{~mm}$ square cross-section were cut out of the pressed slabs along their axis. The bars were then turned to a round cross-section and cut into separate pieces $9 \mathrm{~mm}$ in diameter by $4.5 \mathrm{~mm}$ high. The machining methods and tools used were chosen so as to avoid producing possible surface defects and to ensure the stability of the test results. 
The organoplastic specimens were cut out of a pressed ring of a larger diameter made of the organic aramid fibre with epoxy resin as the binder. The reinforcement geometry consisted of 10 layers of aramid fibre wound at an angle of $\pm 29.3^{\circ}$ to the ring axis. Parallelepipeds $12 \mathrm{~mm}$ by $12 \mathrm{~mm}$ by $8 \mathrm{~mm}$ were cut out in the radial, circumferential, and axial directions relative to the ring axis. The specimens were tested in compression in the cutting directions.

\section{TEST RESULTS AND DISCUSSION}

All the materials were tested under different strain rates, achieved by varying the velocity of the 100 to $300 \mathrm{~mm}$ long striker bars in the range from 10 to $30 \mathrm{~m} / \mathrm{s}$. To assess the experimental scatter 4 or 5 tests were conducted under each set of nominally similar conditions. Dynamic stress-strain diagrams and strain-rate histories were obtained. Unfortunately it is not possible to follow the dynamic stress-strain diagrams down to complete unloading as the duration of both the reflected pulse and the pulse transmitted through the specimen (due to the visco-plastic behaviour of the binding polymer) is considerably longer than that of the incident pulse. Because the length of the pressure bars was insufficient it was not possible to measure all of these longer pulses. In addition to the dynamic tests, static compression tests were also performed.

Figs.1-3 show the stress-strain diagrams for the polyamide, PET, and polycarbonate materials. The strain rate in the experiments varied from 500/s to 5000/s. All the curves obtained are characterized by a non-linear behaviour and lie well above the static diagrams (dotted curves). The various materials tested exhibited different failure behaviours: the specimens of polyamide failed along planes at an angle of $45^{\circ}$ to the loading axis; the PET specimens generally failed on planes lying along the loading axis; the polycarbonate specimens deformed by up to $20 \%$ or more with no visible signs of fracture.

Fig.4 shows the dynamic stress-strain diagrams and the strain-rate histories for the glass-reinforced plastics. Results for unidirectionally reinforced specimens follow curves 2 marked, by the triangles, for cross-ply specimens, curves 1 marked by circles, and for quasi-isotropic specimens, curves 3 marked by diamonds. Specimens which failed during the impact test are shown by solid lines and those which survived by dotted lines. Some non-linearity during loading (and, for elastic behaviour, also during unloading) was observed. The resulting hysteresis loop may be due to the high viscosity of the binding polymer or due to micro-fractures of the specimen structure. The average loading modulus and the fracture stresses are greatest for the cross-ply specimens and least for the quasiisotropic ones.

The static tests reveal the practically linear nature of the deformation process in the glass-reinforced plastics up to fracture. The modulus of elasticity and the fracture stress are almost equal for the unidirectional and cross-ply glass-reinforced plastics with values of $12 \mathrm{GPa}$ and $440 \mathrm{MPa}$, respectively. For the quasi-isotropic glass-reinforced plastic the corresponding values are $12 \mathrm{GPa}$ and $290 \mathrm{MPa}$, respectively. Thus, for all three reinforcement geometries, an increase in modulus and strength is observed between the static and the dynamic tests. The data obtained agrees fairly well, both qualitatively and quantitatively, with the test results described in [6] for glass-reinforced plastic of similar reinforcement geometry and with a binder content of $50 \%$.

Figs. 5-7 summarize the averaged dynamic stress-strain diagrams for the radially, circumferentially and axially loaded organoplastic specimens. The curves are obtained for different strain rates, as indicated on the figures.

Analysis of the loading line for the radial specimens, see fig. 5, reveals that the modulus of compression of the material is practically strain-rate independent. The material unloads, however, in a fairly non-linear manner. The residual deformation of the specimens after loading up to 


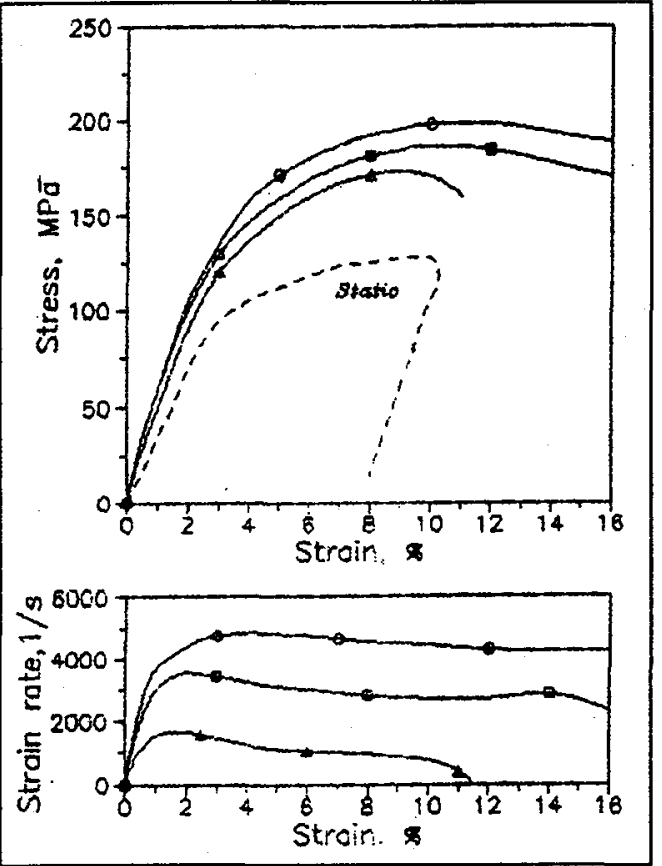

Fig. 1 Stress-strain diagrams for polyamide

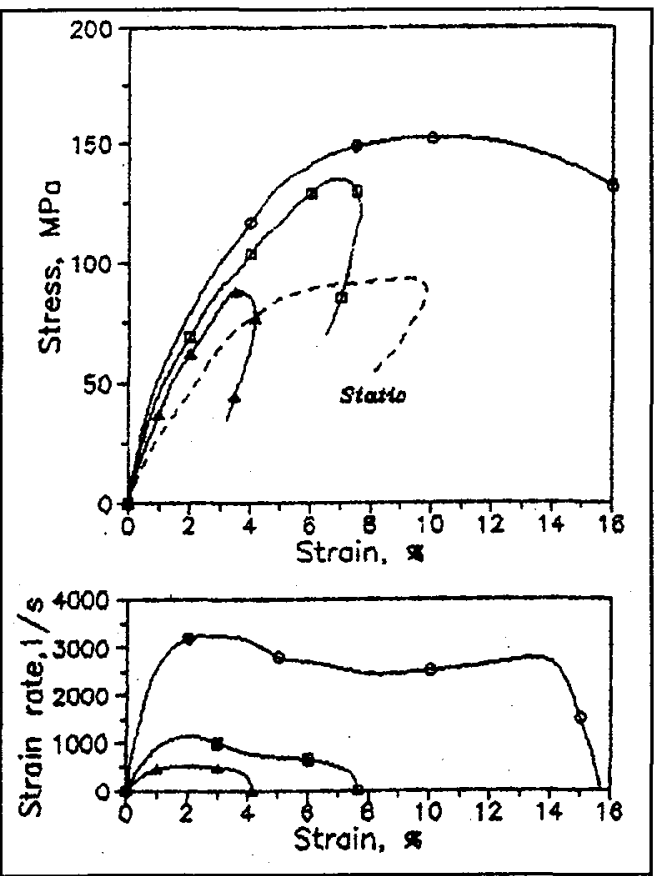

Fig. 3 Stress-strain diagrams for polyethylene terepthalate

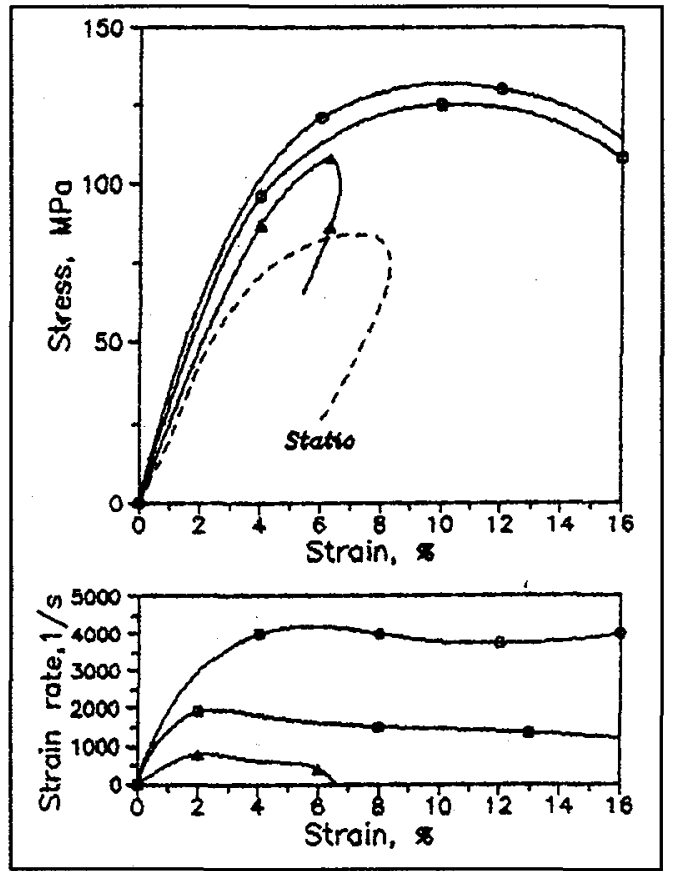

Fig. 2 Stress-strain diagrams for polycarbonate
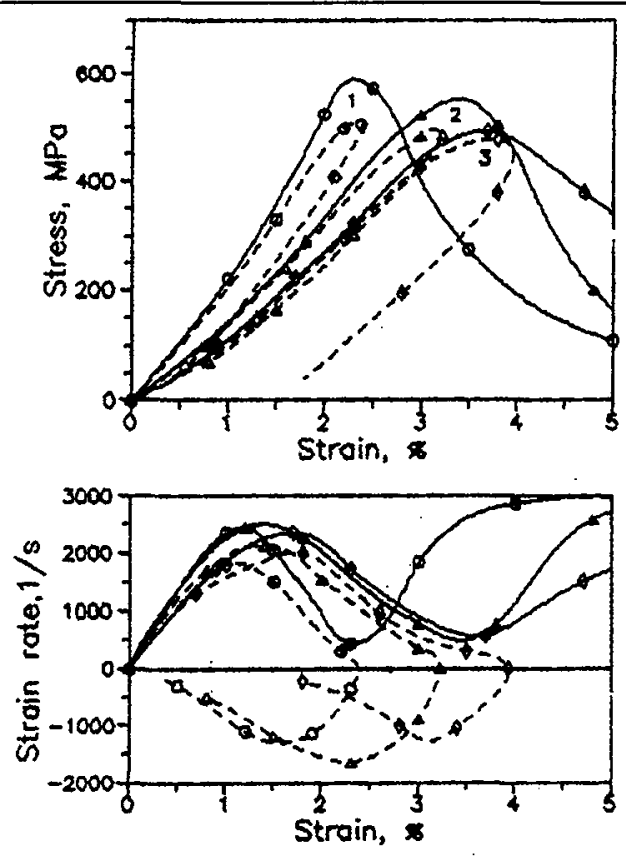

Fig. 4 Stress-strain diagrams for glassreinforced plastic 


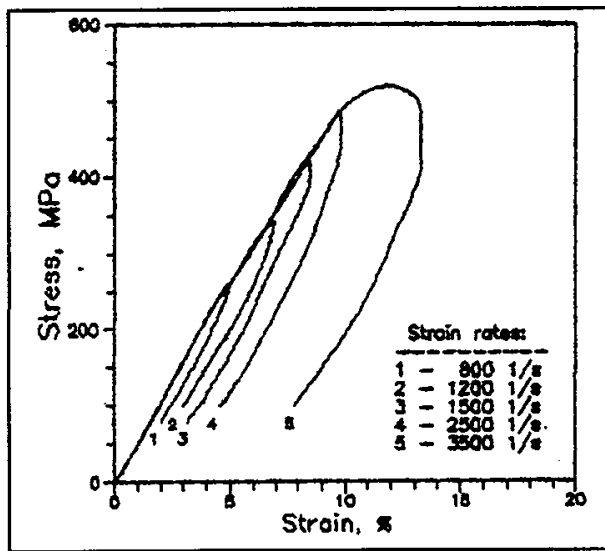

Fig. 5 Dynamic stress-strain diagrams for organoplastic specimens loaded radially

$300 \mathrm{MPa}$ is very small. The appearance of the tested specimens does not practically differ from that of the initial (undeformed) specimens, except for an insignificant extruding of separate fibres from axially oriented layers on each side. At stresses greater than $400 \mathrm{MPa}$ an increase in this extrusion and a corresponding increase in the residual deformation were observed.

The circumferentially loaded specimens exhibited a different type of deformation. As is shown in fig. 6 the loading line is pronouncedly bilinear. On the initial portion, the modulus of elasticity is practically independent of strain rate over the range 600 to $1800 / \mathrm{s}$. The strength is also nearly strain-rate independent. Examination of the appearance of the specimens after loading shows that, once a stress level of $\sim 215 \mathrm{MPa}$ is reached, irrespective of the strain rate, cohesion at the fibre/matrix interface is lost and disintegration takes place. The separated layers lose their stability and bend under the load leading to stress relaxation and a significant increase of deformation in the specimen.

The test results for the axially-loaded specimens show a similar behaviour, see fig. 7. The initial modulus and strength are weakly dependent on strain rate. On reaching a stress level of $\sim 150 \mathrm{MPa}$, the layers lose cohesion and stress relaxation takes place, the unloading behaviour being strain-rate dependent.

\section{CONCLUSIONS}

The results obtained show that the stress-strain diagrams for the three polymers and the glassreinforced plastic are significantly strain-rate dependent, whereas those for the organoplastic specimens exhibited only a fairly weak dependence on strain rate in the range from 500 to $4000 / \mathrm{s}$. 


\section{REFERENCES}

1. Armenakass, A.E. and Sciamarella, C.A., Exp.Mech., 13 (1973) 433-440.

2. Fujii Taichi and Miki Mitsumori, Mem.Fac.Eng., Osak City Univ. N14 (1973) 25-35.

3. Griffiths, L.J. and Martin, D.J., J.Phys.D: Appl.Phys. 7 (1974) 2329-2341.

4. Harding, J. and Welsh, L.M., J.Materials Science 18 (1983) 1810-1826.

5. Whiteney, J.M. and Knight, M., Exp.Mech. 20 (1980) 211-216.

6. Sdao Amijima and Toru Fujii, "Adv. Compos. Mater.", Proc. 3rd Int. Conf., Paris 26-29 August 1980 (Oxford, 1980) 394-413.

7. Kolsky, H., Proc. Phys.Soc. 62 (1949) 676.

8. Davies, E.D.H. and Hunter, S.C., J.Mech.Phys. Solids 11 (1963) 155-179. 